\title{
Assimilation of stream discharge for flood forecasting: The benefits of accounting for routing time lags
}

\author{
Yuan Li, ${ }^{1,2}$ Dongryeol Ryu, ${ }^{1}$ Andrew W. Western, ${ }^{1}$ and Q. J. Wang ${ }^{2}$ \\ Received 16 April 2012; revised 8 February 2013; accepted 25 February 2013; published 18 April 2013
}

[1] General filtering approaches in hydrologic data assimilation, such as the ensemble Kalman filter (EnKF), are based on the assumption that uncertainty of the current background prediction can be reduced by correcting errors in the state variables at the same time step. However, this assumption may not be valid when assimilating stream discharge into hydrological models to correct soil moisture storage due to the time lag between the soil moisture and the discharge. In this paper, we explore the utility of an ensemble Kalman smoother (EnKS) for addressing this time-lag issue. The EnKF and the EnKS are compared for two different updating schemes with the probability distributed model (PDM) via synthetic experiments: (i) updating soil moisture only and (ii) updating soil moisture and routing states simultaneously. The results show that the EnKS is superior to the EnKF when only soil moisture is updated, while the EnKS and the EnKF exhibit similar results when both soil moisture and routing storages are updated. This suggests that the EnKS can better improve the streamflow forecasting for models that do not adopt storage-based routing schemes (e.g., unit-hydrograph-based routing). For models with dynamic routing stores, errors in soil moisture are transferred to the routing stores, which can be corrected effectively by real-time filters. The EnKS-based soil moisture updating scheme is also tested with the GR4H model, for which unit-hydrograph-based routing is used. The result confirms that the EnKS is superior to the EnKF in improving both soil moisture and streamflow forecasting.

Citation: Li, Y., D. Ryu, A. W. Western, and Q. J. Wang (2013), Assimilation of stream discharge for flood forecasting: The benefits of accounting for routing time lags, Water Resour. Res., 49, 1887-1900, doi:10.1002/wrcr.20169.

\section{Introduction}

[2] Flood is one of the most destructive and frequent natural disasters threatening people's lives and properties [Sene, 2008]. Accurate forecasting of river flood with a sufficient lead time plays a significant role in timely flood warning and emergency responses. However, there is scope to reduce error in current flood forecasts. The error arises due to uncertainties in initial conditions, precipitation inputs, and the representation of the flooding process itself [Sene, 2008]. Data assimilation can provide an effective way to reduce the uncertainty in streamflow forecasts by incorporating observations into forecasting models [Kostov and Jackson, 1993; Reichle, 2008].

[3] There are two types of observation data that can be used to improve streamflow forecasting: remotely sensed surface variables and in situ discharge observations. Remotely sensed soil moisture [Crow and Ryu, 2009; Parajka et al.,

\footnotetext{
${ }^{1}$ Department of Infrastructure Engineering, The University of Melbourne, Parkville Victoria Australia.

${ }^{2}$ Land and Water Division, CSIRO, Highett, Victoria, Australia.

Corresponding author: D. Ryu, Department of Infrastructure Engineering, The University of Melbourne, Parkville, Vic 3010, Australia. (dryu@ unimelb.edu.au)

(C)2013. American Geophysical Union. All Rights Reserved. 0043-1397/13/10.1002/wrcr.20169
}

2006; Pauwels et al., 2001] and evapotranspiration (or latent heat flux) [Schuurmans et al., 2003; Zhang et al., 2009] can be assimilated into rainfall-runoff models, while remotely sensed snow data [Clark et al., 2006; Nagler et al., 2008; Slater and Clark, 2006] and brightness temperature [DeChant and Moradkhani, 2011] are used where snowmelt-runoff process is dominant. However, as Pauwels and De Lannoy [2009] pointed out, assimilating remotely sensed data involves converting the remotely sensed signal into state variables either offline or via a built-in observation operator, which is relatively complicated. Even if the remotely sensed state variables are a close approximation of the surface variables, they may not be comparable to the model state variables since most forecasting systems use conceptual models whose state variables do not represent the physical reality [Sene, 2008]. Furthermore, remotely sensed data is often subject to large temporal sampling intervals and coarse spatial resolution relative to the typical size of catchments for operational flood forecasting [Lee et al., 2012]. Therefore, assimilating streamflow is a more popular choice for operational streamflow forecasting [Komma et al., 2008; Lee et al., 2011, 2012; Seo et al., 2009; Thirel et al., 2010].

[4] Assimilation of stream discharge into flood forecasting models has received growing interest in the past decade. Stream discharge assimilation generally employs one of three different approaches: direct discharge error correction, state updating, and parameter updating [Sene, 2008]. The error correction approach directly corrects predicted 
discharge using the discharge observation. This is relatively easy to implement but neither represents the physical processes nor updates the "memory" associated with state variables such as soil moisture storages. Various error correction approaches, including artificial neural network (ANN) models [Anctil et al., 2003; Shamseldin and O'Connor, 2001], parametric simple linear (PSL) models [Goswami et al., 2005], autoregressive moving average (ARMA) models [Broersen, 2007], and ARMA with exogenous input (ARMAX) models [Bogner and Kalas, 2008], have been used to update predicted discharge. State and parameter updating schemes are more popular approaches as they attribute the error in predicted discharge to individual components within the rainfall-runoff process, which is more process based, and the uncertainty reduction in states and parameters is more beneficial for forecasting purposes. The ensemble Kalman filter (EnKF) [Evensen, 1994], which originated from the discrete Kalman filter and the extended Kalman filter, has received significant attention in hydrological data assimilation because the hydrological model does not need to be linearized. The EnKF has been widely implemented for updating both lumped models [Moradkhani et al., 2005b; Pauwels and De Lannoy, 2009; Vrugt et al., 2006, 2005; Weerts and El Serafy, 2006] and distributed models [Andreadis et al., 2007; Clark et al., 2008; Komma et al., 2008; Xie and Zhang, 2010] in streamflow forecasting applications. Another filtering method, the particle filter $(\mathrm{PF})$, is receiving growing attention in hydrological data assimilation due to its ability to handle the propagation of non-Gaussian distributions through nonlinear models [Moradkhani et al., 2005a; Salamon and Feyen, 2009; Weerts and El Serafy, 2006]. The PF can simultaneously update model states and parameters. A number of studies have compared the EnKF and PF. For instance, Weerts and El Serafy [2006] found that the EnKF is less sensitive to the misspecification of the model and input uncertainties than the PF, but DeChant and Moradkhani [2012] found that the PF is more robust and effective than the EnKF. Further, the recently developed particle Markov chain Monte Carlo method appears to provide a more reliable and effective way to assimilate discharge observations [Andrieu et al., 2010; Moradkhani et al., 2012; Vrugt et al., 2013]. Nevertheless, the EnKF remains a popular choice for operational streamflow forecasting purposes [Clark et al., 2008; He et al., 2012; Komma et al., 2008].

[5] For short-term streamflow forecasting (e.g., flood forecasting with lead times from hours to several days), one notable challenge in discharge assimilation is the time lag between the errors in model states (normally soil moisture storages) and predicted discharge. Conceptual flood forecasting models simulate the transfer of water from rainfall to discharge via both rainfall-runoff processes and routing processes. The time lag between soil moisture states and discharge is mostly caused by the routing processes that transfer surface runoff, interflow, and baseflow to catchment discharge. The routing delay depends on various catchment attributes, such as area, mainstream length, topographic slope, and the runoff generation processes. The overall routing time can be represented by the concept of time of concentration. For example, the Engineering and Water Supply Department of South Australia developed an empirical formula for estimating time of concentration based on observed data from 20 catchments in South Australia as [Pilgrim, 1998]

$$
t_{c}=0.5 A^{0.65},
$$

where $t_{c}$ is the concentration time (hours) and $A$ is the catchment area $\left(\mathrm{km}^{2}\right)$.

[6] The routing time delay leads to a time lag between runoff generation and discharge at the catchment outlet and, consequently, a delay between the error in soil moisture states and the error in discharge. This can cause issues when filtering techniques such as the EnKF are applied directly for soil moisture updating, since the filters relate errors in current stream discharge prediction directly to errors in the current soil moisture states.

[7] Some previous studies have considered this time-lag issue when implementing the EnKF-based state updating. For instance, Weerts and El Serafy [2006] set the routing parameter MAXBAS of the HBV-96 model to zero and compared the model prediction with the observation at a later time. This simplification may be acceptable for addressing research questions where the routing is not a crucial process, but it is not appropriate for situations where the routing delay is a critical component for forecasting accuracy. Pauwels and De Lannoy [2009] used a retrospective EnKF with HBV-96 to update the current and past states within a specified time window, $t-n$ to $t$, prior to the flow observation. They then calculate the model prediction by rerunning the entire model from $t-n+1$ to $t+1$. However, as the authors pointed out, model error accumulates as the model runs through the time window, and their approach results in only a marginal improvement of discharge prediction made at time $t$. Another approach that can deal with the time delay is the variational data assimilation, which has been implemented in some operational flood forecasting systems [Lee et al., 2012; Seo et al., 2003, 2009]. A major difference between the sequential approaches (e.g., EnKF and PF) and the variational approach is that the latter is a deterministic technique, which may make it harder to provide a stochastic forecast after updating. The ensemble Kalman smoother (EnKS) provides a potential solution to the time-lag issue in a sequential manner [Evensen and van Leeuwen, 2000]. It uses the EnKF analysis as a first guess and propagates the updating backward in time using the state covariance matrix extended to past time steps. This means that all the past states within the extended analysis time window can be updated by assimilating the current observation. To reduce the computational burden, the EnKS with a fixed time window (or called the fixed-lag EnKS) is usually used to update the state variables within a finite window [Crow and Ryu, 2009; Dunne and Entekhabi, 2006]. To our knowledge, this method has not been applied to stream discharge assimilation. Consequently, despite the apparent need for considering the routing time lag, the benefit of using a lag-aware method such as the EnKS remains unclear.

[8] Various methods exist for routing quick (event) flow and baseflow in rainfall-runoff models. Two common approaches are the unit hydrograph and storage routing. Optimal strategies for assimilating stream discharge (e.g., choice of the variables to be updated, and choice between filtering and smoothing) depend in part on the routing scheme adopted. In this work, we compare two sequential data assimilation methods, the EnKF and the EnKS with a 
fixed analysis time window. The impact of the time lag in assimilating discharge will be demonstrated and the capability of the EnKF and the EnKS to improve flood forecasting via discharge assimilation will be examined. A set of synthetic state updating experiments will be carried out using a conceptual rainfall-runoff model. Specific questions to be addressed in this study are (1) what is the impact of ignoring the time lags between soil moisture states and catchment discharge when the stream discharge is assimilated into a rainfall-runoff model? (2) how much improvement in the model state and stream discharge estimates can be achieved by employing the EnKS to address the time-lag issue, compared with the EnKF? (3) are there any advantages in using the EnKS over the EnKF when dynamic routing storages can be updated simultaneously with the soil moisture?

\section{Methods}

[9] In this paper, a case study will be conducted for the mid-upper part of the Ovens River basin in the southeastern Australia. Four state updating schemes will be implemented and examined through a set of synthetic experiments. To address issues associated with the time lag, an EnKS with a fixed time window is introduced and compared with a control case that uses the EnKF.

\subsection{Rainfall-Runoff Model}

[10] Rainfall-runoff models can be categorized into two groups based on how runoff is routed: unit-hydrographbased routing and storage-based dynamic routing. The unit hydrograph approach applies a fixed distribution of delay times to runoff generated in the catchment. Examples of the models in the first group are the sacramento soil moisture accounting model (SAC-SMA) [Burnash et al., 1973], the modèle du Génie Rural à 4 paramètres Journalier (GR4J) [Perrin et al., 2003] and the Hydrologiska Byråns Vattenbalansavdelning (HBV-96) [Lindström et al., 1997]. For the models with the storage-based routing, the discharge is calculated as a function of the current routing storage levels, and storage levels are tracked dynamically. The second group includes the probability distributed model (PDM) [Moore, 2007] and the conceptual hydrologic model (HyMOD) [Wagener et al., 2001].

[11] Although these two routing approaches are different in the way they represent surface runoff routing, if linear storages are used in the storage routing approach, this approach shares an important mathematical feature with unit hydrographs: their impulse-response functions can be expressed solely by static parameters and are independent of the routing store states, i.e., there is a fixed distribution of delay times. In this study, we employ the PDM with a cascade of two linear storages for quick-flow routing and compare the performance of the EnKF and the EnKS when assimilating stream discharge under the following two updating strategies: (i) updating soil moisture storage only and (ii) updating routing and soil moisture storages simultaneously. Additionally, we confirm our conclusions in Section 4.5 by implementing our updating schemes to a partially unit hydrograph-based routing model, the GR4H model.

\subsubsection{Probability Distributed Model}

[12] The PDM is a conceptual rainfall-runoff model that represents the soil moisture storage with a spatial probabil-

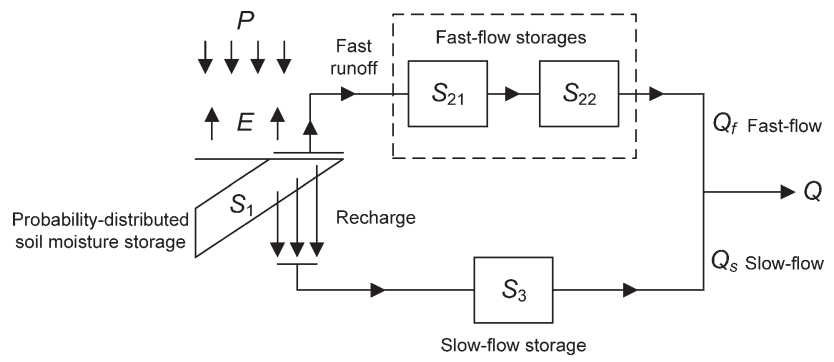

Figure 1. The structure of the PDM with a cascade of two linear storages for fast-runoff routing.

ity distribution function and routes the runoff to the catchment outlet by a fast linear-routing process (nominally event runoff) and a slow nonlinear routing process (nominally baseflow) [Moore, 2007]. Figure 1 shows the structure of the PDM with a cascade of two linear storages $\left(S_{21}\right.$ and $S_{22}$ ) for fast-runoff routing.

[13] The probability-distributed soil moisture storage is an important component of the PDM. Various probability distribution functions have been tested to date, and the Pareto distribution is most widely used. In this research, we use a truncated Pareto distribution for the storage capacity, $c$, with the probability density function $f(c)$ and the cumulative distribution function $F(c)$ given by

$$
\begin{gathered}
f(c)=\frac{b}{c_{\max }-c_{\min }}\left(\frac{c_{\max }-c}{c_{\max }-c_{\min }}\right)^{b-1} \quad c_{\min } \leq c \leq c_{\max }, \\
F(c)=1-\left(\frac{c_{\max }-c}{c_{\max }-c_{\min }}\right)^{b} \quad c_{\min } \leq c \leq c_{\max },
\end{gathered}
$$

where $c_{\min }$ and $c_{\max }$ are the minimum and maximum soil moisture storage capacities ( $\mathrm{mm})$, and $b$ is the exponent of Pareto distribution controlling the degree of spatial variability of the storage capacity.

\subsubsection{Response Function of Discharge to Antecedent Fast Runoffs}

[14] A time window of a specific length needs to be defined when applying the EnKS for state updating. The prediction error at the present time $t$ is assumed to originate from the antecedent model states within the time window $[t-n, t]$. To properly specify the length of the time window, the impact of antecedent states (soil moisture stores) at various time lags on model prediction (discharge) needs to be quantified. The impact of soil moisture stores is delayed by both fast- and slow-routing processes. In our study basin (see description in section 3.1), the fast runoff to total runoff ratio estimated from the calibrated PDM using data from 1999 to 2010 is about $78 \%$, while the ratio increases to about $91 \%$ during the high-flow periods $\left(>20 \mathrm{~m}^{3} / \mathrm{s}\right)$. Given the dominance of the quick-flow pathway in the model, we derive the response function of discharge to antecedent fast runoff, to represent the delay from soil moisture storages to discharge (see Figure 2 and Appendix A).

[15] The discharge $q_{t}^{\prime}$ can be approximated as a weighted average of quick runoff $u$ :

$$
q_{t}^{\prime} \approx \sum_{m=1}^{n} f(m) \cdot u_{t-(m-1)}
$$




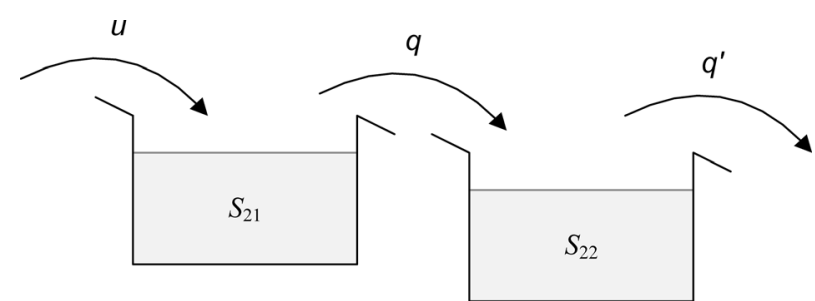

Figure 2. The cascade of two linear storages used for the fast-routing model of the PDM. $u$ is the inflow to the first storage $S_{21}, q$ is the outflow of the first storage, and $q^{\prime}$ is the outflow of the second storage.

where $n$ is the size of the time window (hour), $m$ is the backward time steps (hour), and $t$ is the current time step (hour). For the two linear storage routing used in the PDM, the weighting function $f(m)$ in equation (4) is

$$
\begin{aligned}
& f(m)= \\
& \begin{cases}k_{1} \cdot k_{2} \cdot\left[\left(1-k_{1} \cdot \Delta t\right)^{m}-\left(1-k_{2} \cdot \Delta t\right)^{m}\right] \cdot \Delta t /\left(k_{2}-k_{1}\right) & k_{1} \neq k_{2}, \\
k^{2} \cdot m \cdot(1-k \cdot \Delta t)^{m-1} \cdot(\Delta t)^{2} & k_{1}=k_{2},\end{cases}
\end{aligned}
$$

where $m=1,2,3, \ldots n ; k_{1}$ and $k_{2}$ are the routing parameters $(1 /$ hour $) ; \Delta t$ is the model time step, which is $1 \mathrm{~h}$ in this study. The shape of the weighting function (also called a response function here) with different combinations of $k_{1}$ and $k_{2}$ is shown in Figure 3.

\subsubsection{GR4H Model}

[16] The GR4H model, which is a variant of the GR4J model run with an hourly time step, is employed to further compare the performance of the EnKS and EnKF. GR4H/ GR4J is currently being tested as a candidate model for operational flood forecasting by the Australian Bureau of Meteorology. Preliminary testing shows that, among 13 candidate models, GR4J performs best in 240 test catchments in Australia [Pagano et al., 2010].

[17] The structure of GR4H is shown in Figure 4. The rainfall contribution after interception is divided into direct

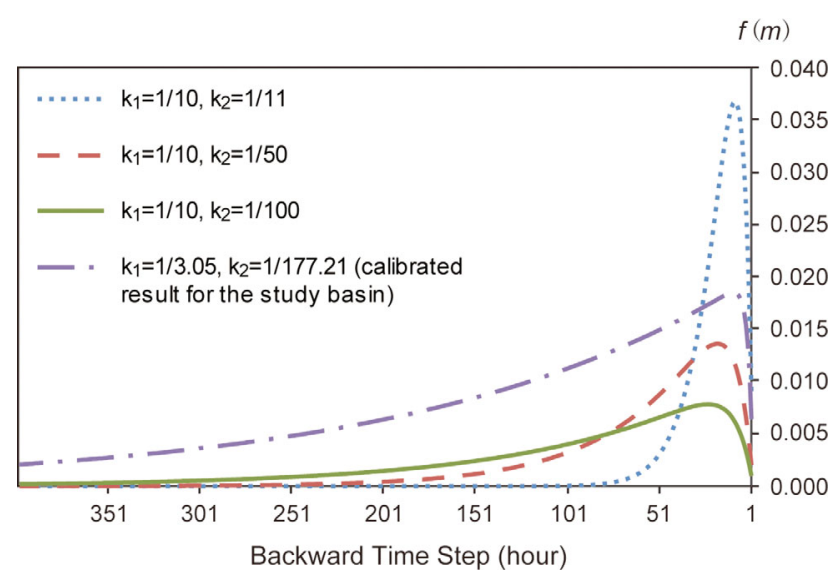

Figure 3. The weighting function $f(m)$ versus past time step $m$ for the PDM's surface routing model with two linear storages.
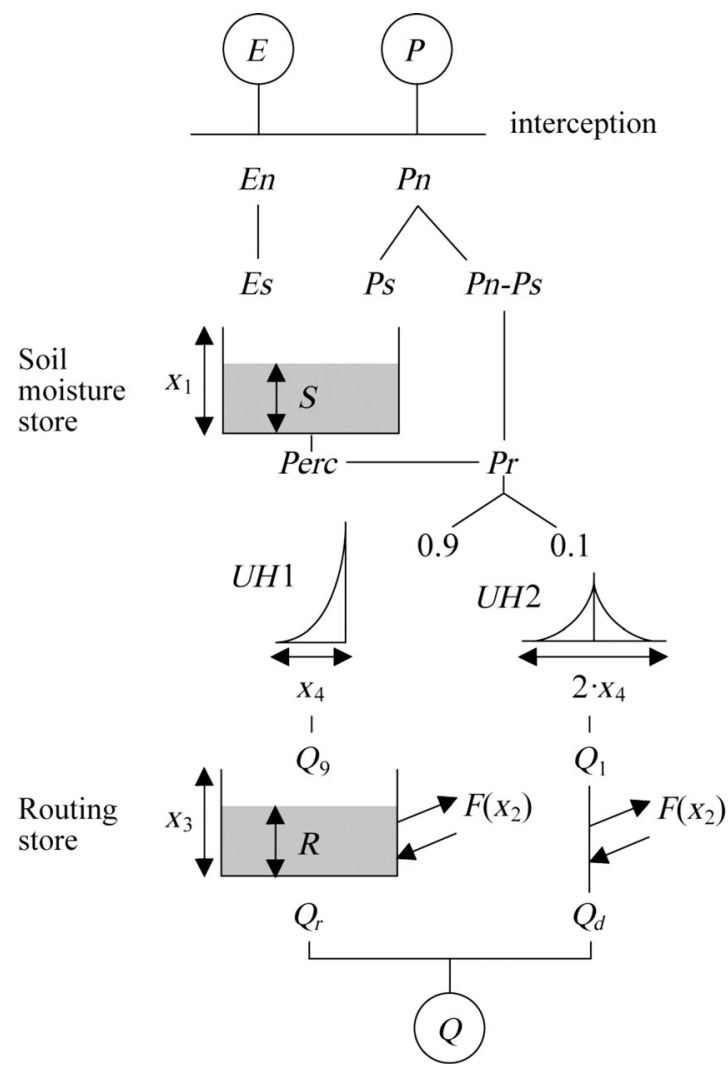

Figure 4. The structure of the GR4H model.

runoff and infiltration into a soil moisture store. Water percolating from the soil moisture store mixes with the direct runoff to form the total runoff. Then the total runoff is partitioned into two routing processes using a fixed ratio. Ninety percent of the runoff is routed by a combination of a unit hydrograph (UH1) and a nonlinear routing storage. The other $10 \%$ is routed by another unit hydrograph (UH2). The length of UH2 is twice that of UH1.

\subsection{State Updating Methods}

\subsubsection{Updating Algorithms}

[18] The state updating algorithms used in this study are the EnKF and the fixed-time-window EnKS. The standard EnKF contains two main steps: model prediction and state updating. In the model prediction step, an ensemble of state variables is transferred within the state space and into the observation space through the following equations:

$$
\begin{gathered}
\mathbf{x}_{t}^{i-}=f\left(\mathbf{x}_{t-1}^{i+}, \mathbf{u}_{t}^{i}, \boldsymbol{\theta}\right)+\boldsymbol{\omega}_{t}^{i} \quad i=1, \quad 2 \ldots N, \\
\hat{\mathbf{y}}_{t}^{i}=h\left(\mathbf{x}_{t}^{i-}, \boldsymbol{\theta}\right),
\end{gathered}
$$

where $\mathbf{x}_{t-1}^{i+}$ is the updated state vector for the previous time step, $t-1 ; \mathbf{x}_{t}^{i-}$ is the predicted state vector for the current time step, $t ; \mathbf{u}_{t}^{i}$ is the input data vector; $\boldsymbol{\theta}$ is the model parameter vector; $\boldsymbol{\omega}_{t}^{i}$ is the model prediction error, which is assumed to follow a Gaussian probability distribution with zero mean; $\hat{\mathbf{y}}_{t}^{i}$ is the observation prediction vector (discharge in our case); and $i$ enumerates a ensemble member of a size- $N$ ensemble. 
[19] In the state updating step, the predicted states are updated using the following equation:

$$
\begin{gathered}
\mathbf{x}_{t}^{i+}=\mathbf{x}_{t}^{i-}+\mathbf{K}_{t}\left(\mathbf{y}_{t}^{i}-\hat{\mathbf{y}}_{t}^{i}\right), \\
\mathbf{y}_{t}^{i}=\mathbf{y}_{t}+\mathbf{\eta}_{t}^{i},
\end{gathered}
$$

where $\mathbf{y}_{t}$ is the observation vector; $\mathbf{y}_{t}^{i}$ is the perturbed observation vector; $\boldsymbol{\eta}_{t}^{i}$ is the observation error, which is assumed to follow a Gaussian probability distribution with zero mean; and $\mathbf{K}_{t}$ is the Kalman gain matrix.

[20] There are several approaches to calculating $\mathbf{K}_{t}$. One relatively effective method used in this research is to calculate $\mathbf{K}_{t}$ using the cross covariance of states and observation predictions:

$$
\mathbf{K}_{t}=\boldsymbol{\Sigma}_{t}^{x y}\left[\boldsymbol{\Sigma}_{t}^{y y}+\boldsymbol{\Sigma}_{t}^{y}\right]^{-1}
$$

where $\Sigma_{t}^{x y}$ is the cross-covariance matrix of the state variables and observation prediction, $\boldsymbol{\Sigma}_{t}^{y y}$ is the error covariance matrix of the observation prediction, and $\boldsymbol{\Sigma}_{t}^{y}$ is the observation error covariance matrix.

[21] The equations for the fixed-time-window EnKS are almost the same as for the EnKF, but with states from multiple time steps in the control state vector [Dunne and Entekhabi, 2006; Evensen and van Leeuwen, 2000]. The model prediction step is exactly the same as the EnKF. The updating step can be formulated as

$$
\mathbf{x}_{t \rightarrow t-n+1}^{i+}=\mathbf{x}_{t \rightarrow t-n+1}^{i-}+\mathbf{K}_{t}^{*}\left(\mathbf{y}_{t}^{i}-\hat{\mathbf{y}}_{t}^{i}\right),
$$

where $n$ is the size of the fixed time window. The Kalman gain is calculated as

$$
\mathbf{K}_{t}^{*}=\boldsymbol{\Sigma}_{t}^{x y *}\left[\mathbf{\Sigma}_{t}^{y y}+\boldsymbol{\Sigma}_{t}^{y}\right]^{-1},
$$

where $\Sigma_{t}^{x y *}$ is the cross covariance matrix of all the state variables within the fixed time window and current observation prediction. The size of the time window can be selected based on the shape of the response function or the unit hydrograph (equation (5) and Figure 3). As the response function of the PDM derived above is a skewed curve whose tail stretches infinitely into the past, including all the time steps in the response function is not practical. For this reason, we adopt a window size so that the integrated response over the window comprises a certain percentage of the integral of the complete response function. The percentage was chosen based on a trade-off between accuracy and computational load (see section 4.1).

\subsubsection{Updating Schemes}

[22] As stated in the introduction, rainfall-runoff models can be categorized into two groups based on how runoff is routed. For the stream discharge assimilation, the optimal state updating strategy may change depending on the routing scheme. To compare the performance of the EnKF and the EnKS in these two routing cases, four assimilation schemes are used in this study. The four schemes are divided into two groups (Table 1). In Group 1, only the soil moisture storage $\left(S_{1}\right)$ is updated. In Group 2, both $S_{1}$ and the routing storages $\left(S_{21}, S_{22}\right.$, and $\left.S_{3}\right)$ are updated simulta-
Table 1. Summary of State Updating Schemes

\begin{tabular}{ll}
\hline Group 1 & Scheme 1: Updating $S_{1}$ only using EnKF \\
& Scheme 2: Updating $S_{1}$ only using EnKS \\
Group 2 & Scheme 3: Updating $S_{1}$ and $S_{21}, S_{22}, S_{3}$ using EnKF \\
& Scheme 4: Updating $S_{1}$ and $S_{21}, S_{22}, S_{3}$ using EnKS
\end{tabular}

neously. Given that the routing storages of the PDM are unchanged, Group 1 is equivalent to comparing EnKF and EnKS for unit-hydrograph-based rainfall-runoff models. Within each group, two updating schemes (the EnKF and the EnKS) are compared. EnKF is used in Schemes 1 and 3 as a control case, while the EnKS is used in Schemes 2 and 4.

[23] Schemes 1-4 are carefully designed to incorporate the unique characteristics of the state updating processes in the EnKF-based and the EnKS-based methods. For the EnKF cases (Schemes 1 and 3), the updating process is conducted between states and discharge observations at the current time step while the prediction is a simple lag-one process. Implementation of the EnKS requires more complex steps and the procedures of Schemes 2 and 4 are illustrated in detail in Figures 5 and 6, respectively.

[24] In Scheme 2 (Figure 5), the updating process works as a continuous prediction-update cycle. In the update step, the EnKS is used to update soil moisture storages $\left(S_{1}\right)$ within the time window from $t-n+1$ to $t$ by assimilating the observed discharge at time $t$. In the prediction step, it is important to recognize that the discharge is related to both the current and antecedent soil moisture states through the routing process. As we are updating past soil moisture storages, this means we have to recalculate the fluxes to estimate discharge (observation estimation). However, as the EnKS is a fully sequential algorithm, we do not need to recalculate the soil moisture from $t-n+1$ to $t$ after updating by the EnKS [Crow and Ryu, 2009; Dunne and Entekhabi, 2006; Evensen and van Leeuwen, 2000]. In brief, in the prediction step we recalculate the runoff fluxes based on the updated soil moisture and rerun the routing process from $t-n+1$ to $t$, and then from $t$ to $t+1$, both the states and discharge are predicted (Figure 5). The important difference between the EnKF and EnKS is that, for the EnKS, the soil moisture storage at any time step $t^{\prime}$, between $t-n+1$ and $t$, contains not only the observation information from $t_{0}$ to $t^{\prime}$ but also the information from $t^{\prime}$ to $t$, whereas the EnKF includes observation information only up to $t^{\prime}$. Therefore, the EnKS-updated soil moisture is expected to be at least as good as that from the EnKF. The forecasting process is separate from the state updating and thus can be conducted at any time step after updating.

[25] Schemes 3 and 4 are designed to update all four storages. The procedure for Scheme 3 is the same as Scheme 1 , except that the control state vector is augmented to contain all four states (soil moisture and routing storages). The procedure for Scheme 4 is illustrated in Figure 6. In this scheme, all the soil moisture and routing storages from $t-n+1$ to $t$ are updated simultaneously using the observed discharge at time $t$. Then the model prediction, including state transfer and observation estimation, is conducted directly from $t$ to $t+1$. In this case, as the routing storages are included in the control state vector and updated directly, there is no need to recalculate the routing states from $t-n+1$ to $t$ after updating by the EnKS. 
LI ET AL.: DISCHARGE ASSIMILATION FOR FLOOD FORECASTING

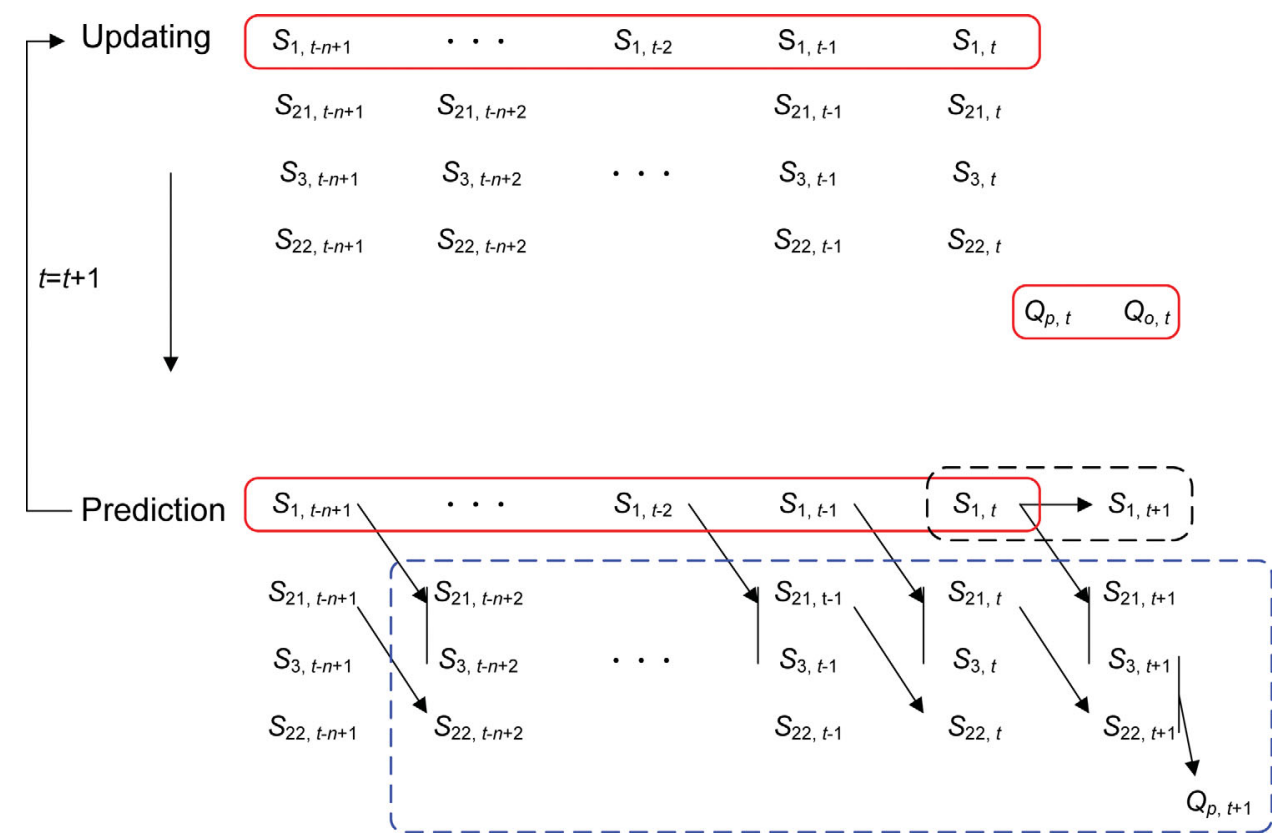

Figure 5. The flowchart for updating the soil moisture storage using the EnKS (Scheme 2). $S_{1}$ is soil moisture storage; $S_{21}, S_{22}$, and $S_{3}$ are routing storages; $n$ is the time window of the EnKS; $Q_{p}$ and $Q_{o}$ are predicted and observed discharge. Red boxes indicate the control states updated by the observation, the black box indicates the state-transfer process, and the blue box indicates the observation estimation.

\section{Study Basin and Data}

\subsection{Study Basin and Data Source}

[26] The study area is the $1210 \mathrm{~km}^{2}$ Ovens River catchment at Myrtleford, southeast Australia. The catchment drains the northern slopes of the Great Dividing Range and is mainly covered by eucalyptus forest.

[27] Data used in this paper include hourly precipitation accumulation, monthly averaged potential evapotranspiration (PET), and hourly accumulation of discharge. The monthly

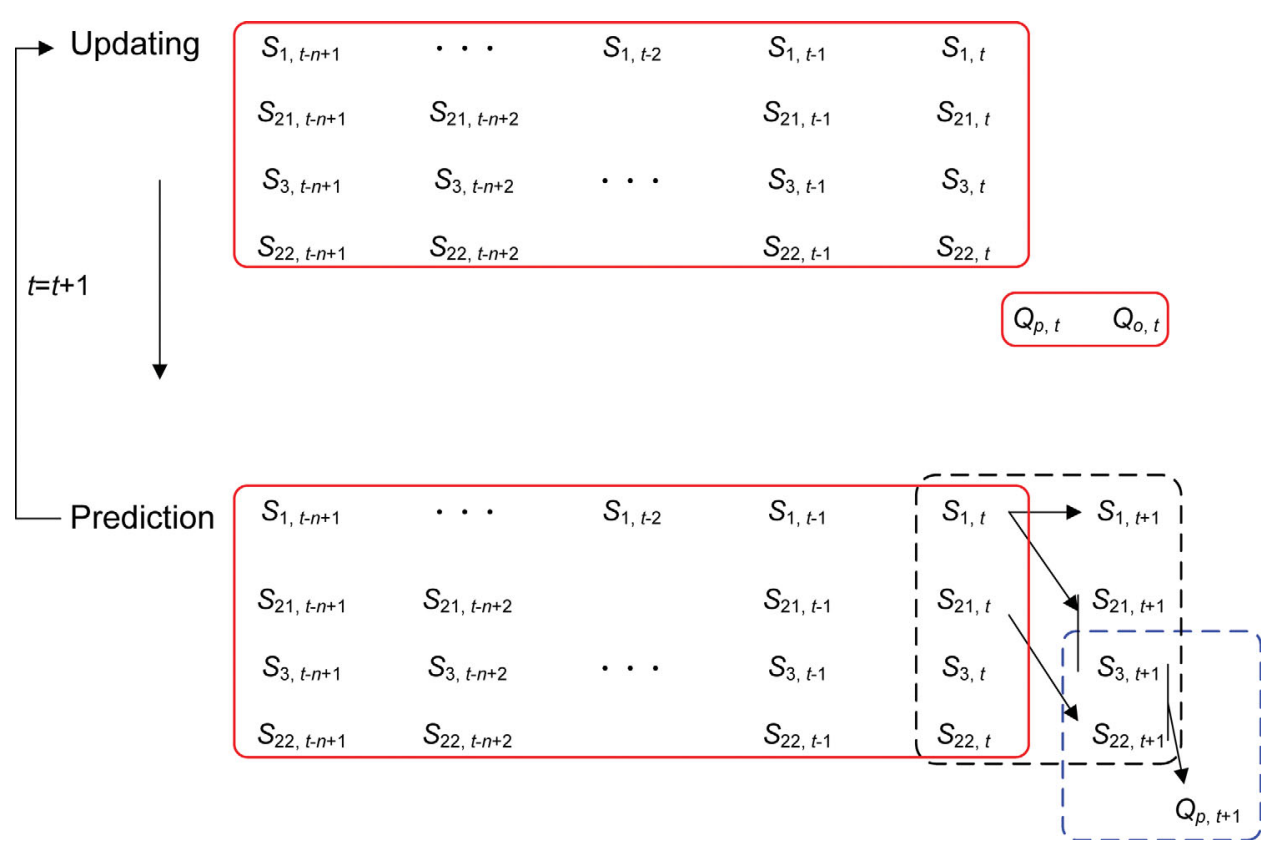

Figure 6. The flowchart for updating the soil moisture and routing storages using the EnKS (Scheme 4). $S_{1}$ is soil moisture storage; $S_{21}, S_{22}$, and $S_{3}$ are routing storages; $n$ is the time window of the EnKS; and $Q_{p}$ and $Q_{o}$ are predicted and observed discharge. Red boxes indicate the control states updated by the observation, the black box indicates the state transfer process, and the blue box indicates the observation estimation. 
PET is the catchment average based on the gridded $(5 \mathrm{~km})$ Australian Water Availability Project (AWAP) data (http:// www.csiro.au/awap/). The hourly precipitation data is interpolated from 14 rain gauges inside or adjacent to the catchment using the inverse distance weighting method with a power of 2, then averaged over the whole study basin. The discharge data are observed by Myrtleford discharge observation station at the outlet of the catchment.

\subsection{Synthetic Data Generation}

[28] As we are conducting synthetic data assimilation experiments, the observed discharge is used only in calibration period for the purpose of developing a realistic model of the catchment. For the synthetic experiments, synthetic truth and observation data are generated before running the data assimilation. The open-loop model runs can be characterized as

$$
\begin{gathered}
\mathbf{x}_{t}=f\left(\mathbf{x}_{t-1}, \mathbf{u}_{t}, \boldsymbol{\theta}\right), \\
\hat{\mathbf{y}}_{t}=h\left(\mathbf{x}_{t}, \boldsymbol{\theta}\right),
\end{gathered}
$$

[29] The synthetic true states are generated by perturbing the state variables with a Gaussian error $\boldsymbol{\omega}_{t}$, and the synthetic discharge observation is generated by perturbing the synthetic true discharge with a Gaussian error $\boldsymbol{\eta}_{t}$

$$
\begin{gathered}
\mathbf{x}_{t}^{\text {truth }}=f\left(\mathbf{x}_{t-1}^{\text {truth }}, \mathbf{u}_{t}, \boldsymbol{\theta}\right)+\boldsymbol{\omega}_{t}, \\
\hat{\mathbf{y}}_{t}^{\text {truth }}=h\left(\mathbf{x}_{t}^{\text {truth }}, \boldsymbol{\theta}\right) \\
\mathbf{y}_{t}^{\text {obs }}=\hat{\mathbf{y}}_{t}^{\text {truth }}+\boldsymbol{\eta}_{t},
\end{gathered}
$$

[30] In the PDM, the net precipitation is partitioned into surface runoff and infiltration. Due to the dynamic routing storages, the error from input forcing data is transferred to the soil moisture and routing stores. During the rainfall-runoff and routing processes, the uncertainty in model parameters also contributes to the errors in model state variables. Therefore, model state variables need to be appropriately perturbed to represent realistic error-propagation process. Based on the assumption that the states contain all the errors from input data and model parameters, a range of state perturbation schemes are trialed for generating the synthetic truth. The error distributions are assumed to be Gaussian. Different combinations of error standard deviation $(\sigma)$ are tried until the resulting discharge yielded a reasonable uncertainty range, which is assumed to be approximately $20 \%$ of the discharge prediction. The final choice of the perturbation noise for each state used in this study is summarized in Table 2. Due to the high autocorrelation of the error in soil moisture storage $\left(S_{1}\right)$, the Gaussian error with $\sigma=1$ $\mathrm{mm}$ is accumulated in $S_{1}$ and leads to a realistic ensemble soil moisture storages $\left(S_{1}\right)$ spread, which is about $50 \mathrm{~mm}$

Table 2. Standard Deviations of Synthetic State and Discharge Errors

\begin{tabular}{cccccc}
\hline Variables & $S_{1}$ & $S_{21}$ & $S_{22}$ & $S_{3}$ & $Q_{\text {obs }}$ \\
\hline Standard deviation & $1 \mathrm{~mm}$ & $1 \%$ & $1 \%$ & $1 \%$ & $5 \%$ \\
\hline
\end{tabular}
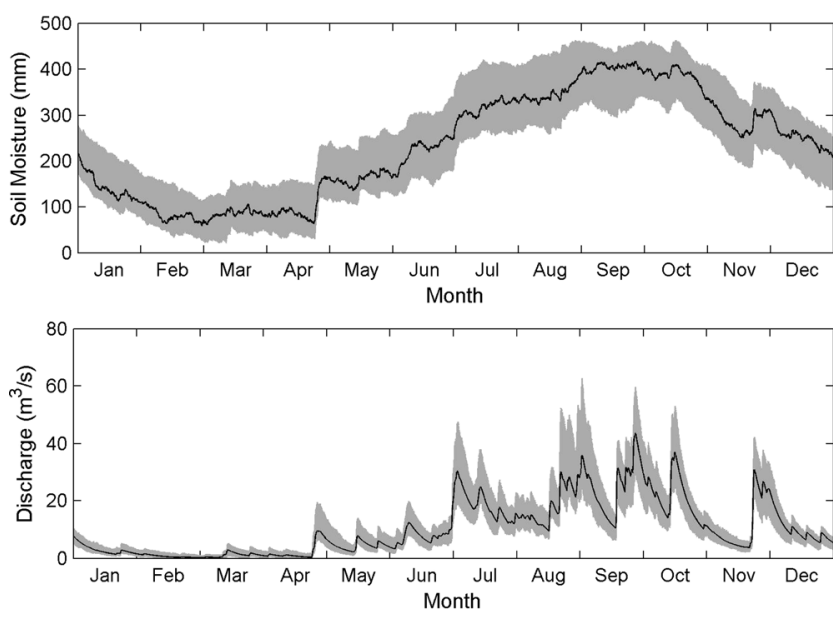

Figure 7. The spread of synthetic soil moisture and discharge based on the state perturbation scheme in 2009. The solid line is the synthetic truth. The gray range represents the $95 \%$ confidence interval of the ensemble spread.

(Figure 7). The routing storages $S_{21}, S_{22}$, and $S_{3}$ are perturbed with $\sigma$ set to $1 \%$ of the state value. The reason we use a multiplicative error to perturb the routing storages is because the routing storages highly depend on the input rainfall, and large storms normally bring larger uncertainty. This perturbation scheme leads to a discharge error of approximately $20 \%$, which is close to the prediction error of the PDM during the calibration periods. To create the synthetic observed discharge ( $\left.Q_{\text {obs }}\right)$, a Gaussian error of $5 \%$ is assumed and added to the open-loop discharge.

[31] An identical perturbation scheme is used in ensemble generation in the EnKF and the EnKS. This means that the ensemble spread is consistent with the uncertainty in the synthetic data and also consistent between all the different cases considered.

\section{Results and Discussion}

\subsection{Model Calibration and Time Window Selection}

[32] The PDM is calibrated using observed rainfall, PET, and discharge data from 1 January 1999 to 21 July 2004 and using the shuffled complex evaluation (SCE) algorithm [Duan et al., 1992]. The calibrated routing parameters $k_{1}$ and $k_{2}$ are $1 / 3.05 \mathrm{~h}^{-1}$ and $1 / 177.21 \mathrm{~h}^{-1}$, respectively, which leads to a response function with a quick rise followed by a very slow recession (Figure 3 ). The peak delay occurs in about $14 \mathrm{~h}$. As mentioned in section 2.2.1, choosing a long time window leads to large computational burden while a small window includes less of the overall response. With these considerations in mind, $215 \mathrm{~h}$ was chosen as the time window, which accounts for $70 \%$ of the response function. In other words, $70 \%$ of the surface runoff generated in one time step reaches the catchment outlet within $215 \mathrm{~h}$. It should be noted that the PDM is a conceptual model, and the fast-routing process is likely to represent routing of runoff resulting from a combination of event runoff processes including surface runoff and interflow.

[33] To confirm the validity of the response function and the chosen time window, the correlation coefficient between errors in soil moisture storage $\left(S_{1}\right)$ and errors in discharge 


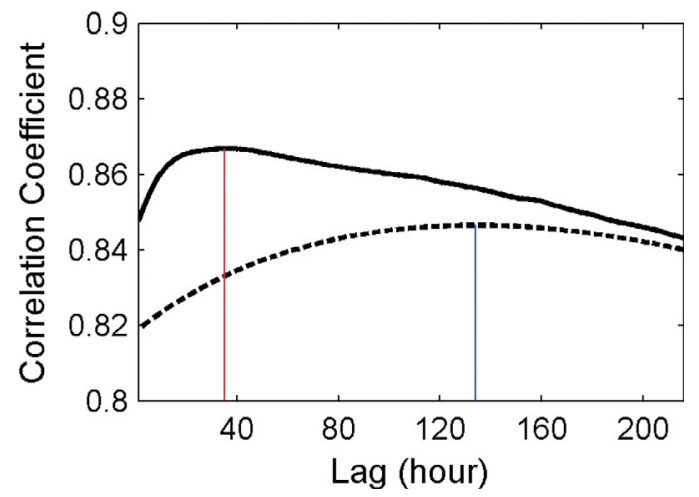

Figure 8. The correlation coefficient between errors in soil moisture storage $\left(S_{1}\right)$ and errors in discharge with increasing time lag. The dashed curve is the correlation coefficient for the entire period, and the solid curve is the correlation coefficient for the time steps with rainfall occurrence. The blue and red lines indicate the highest correlation in these two cases.

versus time lag was calculated based on an open loop ensemble prediction (Figure 8). The highest correlation calculated based on the entire period from 1999 to 2010 is at the lag of $134 \mathrm{~h}$, while the highest correlation calculated only during rainfall occurrence is at the lag of $34 \mathrm{~h}$. The delay is much larger for the entire period because during dry periods, no fast runoff is generated, and errors in soil moisture will be propagated only through baseflow routing. Even during rainfall events, part of the error is routed by slow runoff. Moreover, the errors in soil moisture feature high temporal correlation. Therefore, the slow-routing component will delay the peak correlation. This explains why the actual peak correlation during rainfall events appears at a longer lag $(34 \mathrm{~h})$ compared with the peak of the fast-routing response function $(14 \mathrm{~h})$.

\subsection{State Updating}

[34] Continuous state updating with 100 ensemble members is conducted from 22 July 2004 to 20 August 2010. Forecasting with fixed lead times of $1,6,12,24$, and $48 \mathrm{~h}$ are conducted for each time step based on the updated states. Generally, the performance of the ensemble forecasting is evaluated in terms of accuracy and reliability. However, there is little need of evaluating the reliability because the prediction errors in this synthetic experiment are calibrated to result in reliable ensemble realizations. The temporal mean of the root-mean-square error (MRMSE) of 100 realizations, which can summarize errors reflected in the individual ensemble members, is calculated to quantify the accuracy of the ensemble states and discharge forecasts as follows:

$$
\text { MRMSE }=\frac{\sum_{t=1}^{L} \sqrt{\sum_{i=1}^{N}\left(\mathbf{x}_{t}^{i}-\mathbf{x}_{t}^{\text {truth }}\right)^{2} / N}}{L},
$$

where $N$ is the ensemble size (100) and $L$ is the total time step of evaluation (updating/forecasting) period $(53,291 \mathrm{~h})$. Table 3 summarizes the MRMSE for the analyzed soil
Table 3. MRMSE of Analyzed States and Forecast Streamflow

\begin{tabular}{lcccccc}
\hline MRMSE & Unit & Open Loop & Scheme 1 & Scheme 2 & Scheme 3 & Scheme 4 \\
\hline$S_{1, t-n}$ & $\mathrm{~mm}$ & & & 12.891 & & 12.118 \\
$S_{1, t}$ & & 37.580 & 26.741 & 17.328 & 16.129 & 16.132 \\
$S_{3, t}$ & & 0.270 & 0.154 & 0.141 & 0.102 & 0.102 \\
$S_{21, t}$ & & 0.020 & 0.012 & 0.007 & 0.006 & 0.006 \\
$S_{22, t}$ & 1.248 & 0.537 & 0.446 & 0.230 & 0.229 \\
$Q_{t+1}{ }^{3} / \mathrm{s}$ & 2.9540 & 1.203 & 1.036 & 0.308 & 0.308 \\
$Q_{t+6}$ & & 2.9540 & 1.206 & 1.042 & 0.414 & 0.414 \\
$Q_{t+12}$ & 2.9540 & 1.216 & 1.051 & 0.511 & 0.510 \\
$Q_{t+24}$ & 2.9540 & 1.249 & 1.073 & 0.658 & 0.658 \\
$Q_{t+48}$ & 2.9540 & 1.331 & 1.123 & 0.867 & 0.867 \\
\hline
\end{tabular}

moisture storage $\left(S_{1}\right)$ at the current time step $(t)$ and the beginning of the time window $(t-n)$, the routing storages $\left(S_{21}, S_{22}, S_{3}\right)$ at current time step $(t)$, and the discharge forecasts with the lead times of $1,6,12,24$, and $48 \mathrm{~h}$.

4.2.1. Updating Soil Moisture Storage $\left(S_{1}\right)$ Only

[35] The temporal changes in MRMSE summarized in Table 3 indicate that the EnKS (Scheme 2) outperforms the EnKF (Scheme 1) in updating $S_{1}$. The MRMSE of $S_{1}$ at the current step $(t)$ decreases from 26.7 to $17.3 \mathrm{~mm}$, while the MRMSE of $S_{1}$ at the initial step of the time-lag window $(t-n)$ analyzed by the EnKS is $12.9 \mathrm{~mm}$. These results are also evident by comparing Figures $9 \mathrm{a}$ and $9 \mathrm{~b}$, which show that the uncertainty of analyzed $S_{1}$ is much wider for Scheme 1 than Scheme 2.

[36] Although the routing storages are not directly updated, there are still moderate improvements in routing storages for Scheme 2 compared with Scheme 1, due to the transfer process from $S_{1}$ to $S_{21}, S_{22}$ and $S_{3}$ (Table 3). Nevertheless, the improvements in the routing storages, especially $S_{22}$ and $S_{3}$, are less significant than in $S_{1}$ due to the effect of perturbing the routing storages in the ensemble-generation process. Since the accuracy of the routing storages, especially $S_{22}$, is more directly linked to the accuracy of forecast discharge, the improvement in discharge forecasts for Scheme 2 compared with Scheme 1 is not as significant as $S_{1}$. For instance, the MRMSE of $1 \mathrm{~h}$ forecast discharge improves from 1.20 to $1.04 \mathrm{~m}^{3} / \mathrm{s}$ for Schemes 1 and 2 , respectively. This pattern of improvement persists from 1 to $48 \mathrm{~h}$ forecasts, (the MRMSE of $48 \mathrm{~h}$ forecasts decreases from 1.33 to $1.12 \mathrm{~m}^{3} / \mathrm{s}$ ), because the larger improvement of the $S_{1}$ in Scheme 2 propagates through the routing storages to improve the discharge forecasts. Figures $9 \mathrm{c}-9 \mathrm{f}$ show the $48 \mathrm{~h}$ discharge forecasts in Schemes 1 and 2. The spread of the forecast discharge is narrower in Scheme 2 than in Scheme 1.

[37] Table 4 shows the discharge forecast improvement during high-flow periods in terms of MRMSE. The thresholds of $20 \mathrm{~m}^{3} / \mathrm{s}$ and $50 \mathrm{~m}^{3} / \mathrm{s}$, which roughly correspond to minor and moderate flood levels, are used to extract the high-flow periods. The ratio of the MRMSE of the EnKS (Scheme 2) to that of the EnKF (Scheme 1) is calculated to quantify the improvement. A smaller ratio (Scheme 2/ Scheme 1) indicates greater improvement. While this ratio is about the same for the $20 \mathrm{~m}^{3} / \mathrm{s}$ threshold and the whole period, the improvement in performance of the EnKS compared with the EnKF is greater for the $50 \mathrm{~m}^{3} / \mathrm{s}$ threshold. This is also evident from visual examination of Figures $9 \mathrm{e}$ and $9 \mathrm{f}$. The enhanced performance of the EnKS during 

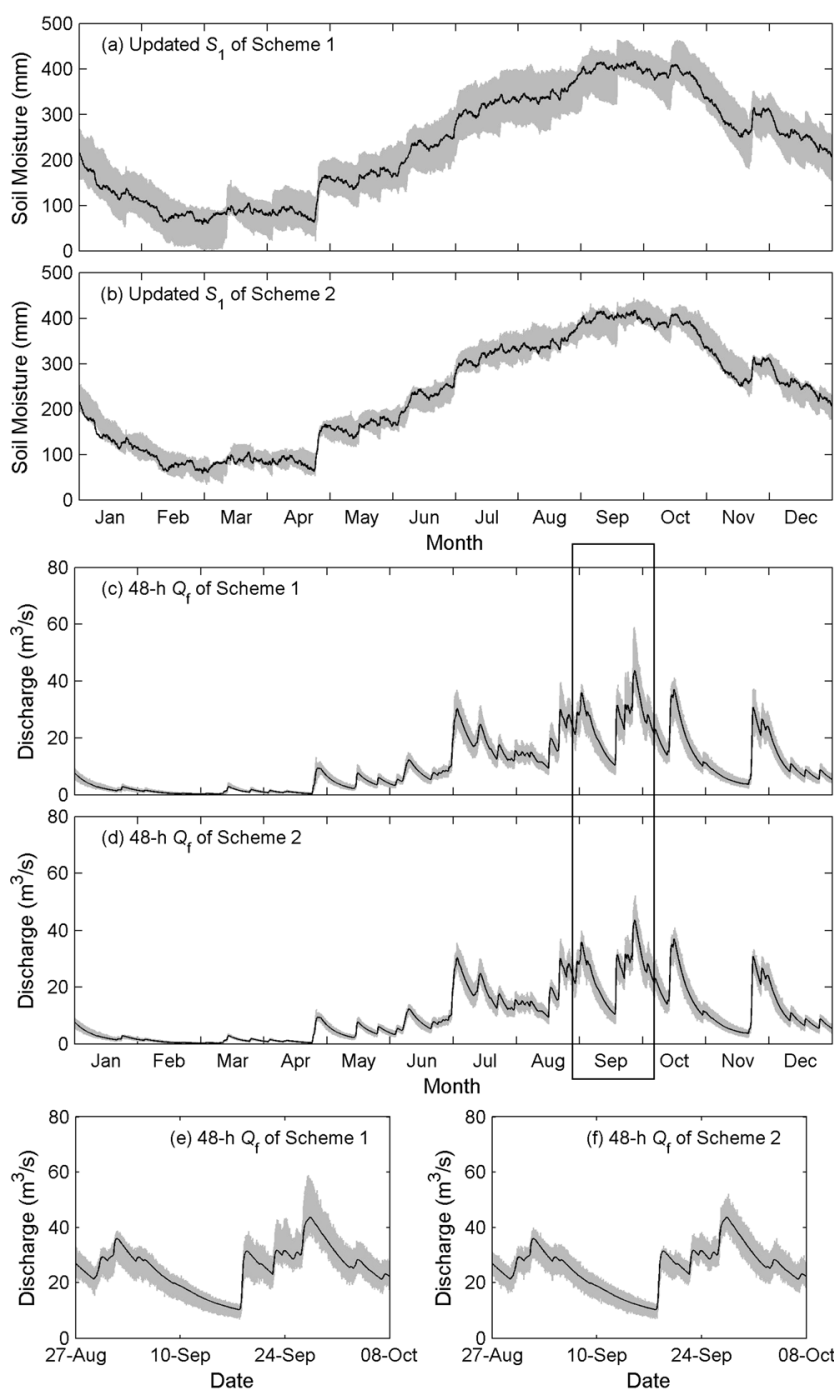

Figure 9. Updating and forecasting results for Schemes 1 and 2 in 2009. (a and b) The spread of updated $S_{1}$ at time $t$. (c and d) The spread of the forecast discharge with a lead time of $48 \mathrm{~h}$. (e and f) Details of the period with the largest events. The solid lines are the synthetic truth and the gray ranges represent the $95 \%$ confidence interval of the ensemble spread.

high-flow periods is due to the increased fraction of total runoff routed through the fast-routing pathway, compared with low-flow periods. This is because the accuracy of discharge prediction is more sensitive to soil moisture within the analysis time window when fast runoff is dominant.

\subsubsection{Updating Both Soil Moisture and Routing Storages}

[38] The EnKF (Scheme 3) and EnKS (Scheme 4) demonstrate similar improvements in forecast discharge when the soil moisture $\left(S_{1}\right)$ and the routing storages $\left(S_{21}, S_{22}, S_{3}\right)$ are updated together. The MRMSE of the analyzed states at current time step are very similar, and thus the similarity in states in turn leads to similar forecast discharges (Table 3). For instance, in Figure 10, the 95\% confidence intervals of the analyzed $S_{1}$ at the current time step and of the $48 \mathrm{~h}$ forecast discharge vary within a very similar range for these two schemes. This result can be explained by the fact that the errors in soil moisture up to the present time step (within the EnKS analysis time window) accumulate in the routing states. Thus, once the routing state errors are corrected, further correction of errors in past soil moisture provide no additional benefit for improving stream discharge. In other words, the state error transfer process becomes equivalent to a lag-one process (Markov process) in terms of the state error correction. As a result, when the routing states are updated by the filter/smoother, the EnKF can correct the forecast discharge errors as effectively as the EnKS.

[39] One difference between the EnKF and EnKS when the routing states are updated is that the analyzed past soil moisture could be more accurate for the EnKS than for the EnKF. For instance, Table 3 shows that soil moisture at time $t-n$ is more accurate for the EnKS than for the EnKF. This is because the analyzed past soil moisture is updated not only by the current and further past observations but also by "future" observations (i.e., from the time period $[t-n$, $t]$ ). Therefore, relatively more observations contribute to correct the soil moisture error in the EnKS analysis than in the EnKF analysis [Dunne and Entekhabi, 2006; Evensen and van Leeuwen, 2000]. However, more accurate soil moisture in the past time steps exerts insignificant influence on the forecast discharge due to the updated routing states.

\subsection{Consequences of Ignoring the Time Lag}

[40] As mentioned earlier, the EnKF performs worse than the EnKS when only soil moisture is updated (Schemes 1 and 2) for both the state estimation and for discharge forecasts. Relatively poor performance of the EnKF can be partially explained by its overcorrection of soil moisture error.

[41] The errors in predicted discharge and observed discharge are usually temporally correlated [Schoups and Vrugt, 2010] and the autocorrelation can be fairly high. For example, the lag-one autocorrelation of differences between predicted and observed discharge in this study is around 0.7 during the calibration period. Thus, if the discharge is underestimated (overestimated) at a certain time step, the discharge in the subsequent time step is likely to be underestimated

Table 4. Improvement Ratio of Scheme 2 Compared With Scheme 1 for Discharge Forecasts

\begin{tabular}{|c|c|c|c|c|c|c|c|c|c|}
\hline \multirow[b]{2}{*}{$\operatorname{MRMSE}\left(\mathrm{m}^{3} / \mathrm{s}\right)$} & \multicolumn{3}{|c|}{ Entire Period } & \multicolumn{3}{|c|}{ Events Above $20 \mathrm{~m}^{3} / \mathrm{s}$} & \multicolumn{3}{|c|}{ Events Above $50 \mathrm{~m}^{3} / \mathrm{s}$} \\
\hline & Scheme 1 & Scheme 2 & Scheme 2 /Scheme 1 & Scheme 1 & Scheme 2 & Scheme 2 /Scheme 1 & Scheme 1 & Scheme 2 & Scheme 2 /Scheme 1 \\
\hline$Q_{t+1}$ & 1.203 & 1.036 & $86.1 \%$ & 2.908 & 2.431 & $83.6 \%$ & 5.753 & 4.334 & $75.3 \%$ \\
\hline$Q_{t+6}$ & 1.206 & 1.042 & $86.4 \%$ & 2.916 & 2.449 & $84.0 \%$ & 5.778 & 4.393 & $76.0 \%$ \\
\hline$Q_{t+12}$ & 1.216 & 1.051 & $86.4 \%$ & 2.946 & 2.480 & $84.2 \%$ & 5.890 & 4.530 & $76.9 \%$ \\
\hline$Q_{t+24}$ & 1.249 & 1.073 & $85.9 \%$ & 3.054 & 2.557 & $83.7 \%$ & 6.347 & 4.991 & $78.6 \%$ \\
\hline$Q_{t+48}$ & 1.331 & 1.123 & $84.3 \%$ & 3.316 & 2.737 & $82.5 \%$ & 7.351 & 5.987 & $81.4 \%$ \\
\hline
\end{tabular}



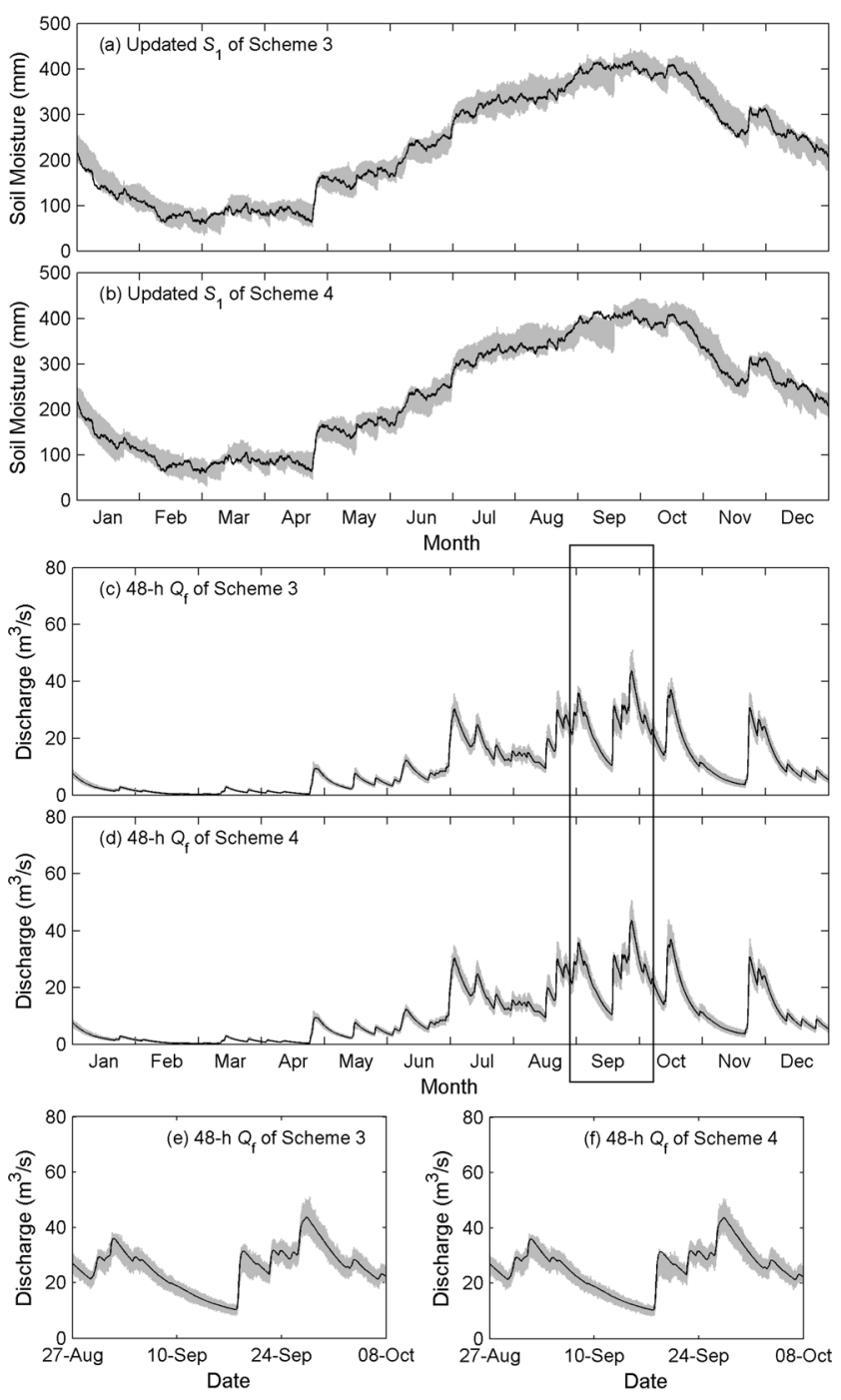

Figure 10. Updating and forecasting results for Schemes 3 and 4 in 2009. (a and b) The spread of updated $S_{1}$ at time $t$. (c and d) The spread of the forecast discharge with a lead time of $48 \mathrm{~h}$. (e and f) Details of the period with the largest events. The solid lines are the synthetic truth and the gray ranges represent the $95 \%$ confidence interval of the ensemble spread.

(overestimated) too. Also, when the EnKF is applied to update $S_{1}$ only (Scheme 1), the impact of error correction in the time step is not realized in the discharge prediction of the next time step due to the routing time delay. Thus, the filter will continue to adjust $S_{1}$ in the same direction in the next time step(s) and that leads to overcorrection of $S_{1}$ [Li et al., 2011]. This can be interpreted as the EnKF attributing the error in current discharge all to the current soil moisture, whereas, in fact, the past soil moisture was the primary cause of the current discharge error. This would not be a problem if the correlation between current soil moisture storage and discharge prediction is low. However, the high autocorrelation of soil moisture means the correlation between moisture storage and discharge is still high (Figure 8). Therefore, the overcorrection can be quite a significant issue in Scheme 1 . Figure 11 shows that the synthetic truth and ensemble means

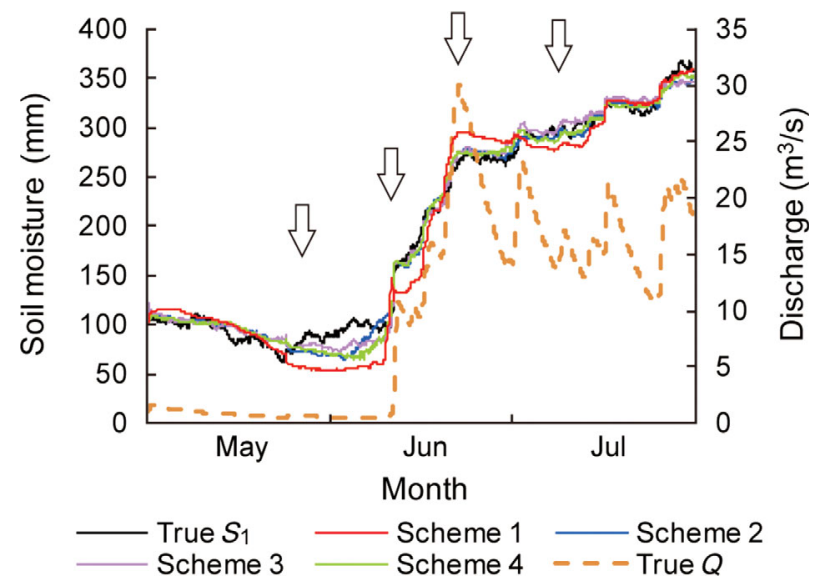

Figure 11. The synthetic true discharge, synthetic true $S_{1}$, and ensemble means of $S_{1}$ updated by each of the four schemes in May, June, and July 2005. Dashed curve is discharge and solid curves are soil moistures.

of $S_{1}$ updated by the four schemes in May-July 2005. The arrows emphasize the periods during which $S_{1}$ is significant overcorrected by Scheme 1.

[42] It is worth noting again that this issue does not appear in Scheme 3. This is because the errors in antecedent $S_{1}$ are propagated into the routing storages. In other words, routing storages have memories of the past soil moisture uncertainty. Consequently, updating the routing storages properly corrects these "old" errors.

\subsection{Challenges in Soil Moisture Updating During Dry Periods}

[43] The impact of correcting soil moisture error on stream discharge may become marginal during dry periods. This is due to the fact that during the prolonged period of no rain, errors in soil moisture are mainly routed through the baseflow process, which is much slower than the surface routing process. This also results in significantly weaker error covariance between the stream discharge and the soil moisture. Moreover, when the soil water storage falls below the tension storage capacity in the PDM, drainage to the baseflow store becomes zero and is thus unaffected by soil water storage. This means that under such conditions there is no connection between soil moisture errors and discharge errors.

[44] In our study catchment, the weak error covariance is observed at times during the specific period of a year in, e.g., February to April in 2009 (Figure 7); however, it would be more prevalent in drier environments. Given this lack of information transfer (i.e., decoupling of stream discharge from soil moisture), neither the filter nor the smoother can effectively adjust soil moisture storage during no rain and dry periods. In this case, assimilating observed soil moisture might be a better choice for soil moisture analysis. However, reduced efficiency during dry periods may not be a serious concern for flood forecasting as we are mostly concerned with larger peak flows.

\subsection{Implementation of the EnKS for the GR4H Model}

[45] Our analyses so far are based on a model that includes storage routing, and the best strategy is found to 
update both the soil moisture and routing stores. Further, we find that the EnKS is a better choice than the EnKF if only soil moisture is updated, but they are equally effective when the routing states and soil moisture are updated simultaneously. Here we apply the EnKS to a rainfall-runoff model that adopts in part a unit-hydrograph-based routing. For the implementation of the EnKS, a time window with an equal size (calibrated to $46 \mathrm{~h}$ ) to the length of UH2 is used here. The synthetic truth is generated by adding Gaussian error with a standard deviation of $1 \mathrm{~mm}$ at each time step to the soil moisture storage, and the synthetic observation is generated by adding a multiplicative Gaussian error with a standard deviation of $5 \%$ to the synthetic true discharge. Two updating schemes are implemented: (1) updating the soil moisture storages $(S)$ and the routing storage $(R)$ with the EnKF and (2) updating these two storages with the EnKS. The resulting MRMSE of the analyzed states and forecast streamflow, as well as the ratio between the two schemes, are summarized in Table 5.

[46] The results from GR4H confirm the conclusions drawn from the experiment using the PDM (Schemes 1 and 2). Although there is a routing storage updated by the EnKF/ EnKS, updating antecedent soil moisture still leads to updates in the discharge through $\mathrm{UH} 1$ and $\mathrm{UH} 2$, and this process avoids overcorrection of the current states. Therefore, the EnKS outperforms the EnKF in both analyzed states and forecast discharge. The ratios of MRMSE of the EnKS to the EnKF in analyzed soil moisture and routing storages are $95.9 \%$ and $93.9 \%$ respectively, which are not as significant as the improvements in Scheme 2 against Scheme 1 of the PDM-based experiment. This is attributed to the fact that, in GR4H, only a small fraction of runoff is routed via each of the unit hydrographs. However, the improvements in shortterm forecasts (1-12 h) are still fairly significant. For example, the ratio of MRMSE for the $1 \mathrm{~h}$ forecast is $87.6 \%$. This is due to the fact that the forecast discharges contain accumulated information of the antecedent soil moisture values within the time steps of the unit hydrographs, which is updated more effectively by the EnKS. This can be confirmed by the evidence that the MRMSE of analyzed soil moisture at the beginning of the lag window $(t-n)$ is $10.1 \mathrm{~mm}$, whereas it increases to $13.1 \mathrm{~mm}$ at the end of the analysis time window. Finally, as the lead time increases, the benefit of the EnKS reduces due to the added uncertainty in forecast time steps. The ratio of MRMSE for the $48 \mathrm{~h}$ forecast discharge is $95.9 \%$.

\section{Summary and Conclusions}

[47] To address the time-lag issue in stream discharge assimilation, two groups of synthetic state updating experi-

Table 5. MRMSE of Analyzed States and Forecast Streamflow Using GR4H

\begin{tabular}{lcccc}
\hline MRMSE & Unit & EnKF & EnKS & EnKS/EnKF \\
\hline$S_{t-n}$ & $\mathrm{~mm}$ & 13.637 & 10.094 & $74.1 \%$ \\
$S_{t}$ & & 13.637 & 13.078 & $95.9 \%$ \\
$R_{\mathrm{t}}$ & & 0.320 & 0.301 & $93.9 \%$ \\
$Q_{t+1}$ & $\mathrm{~m}^{3} / \mathrm{s}$ & 0.194 & 0.170 & $87.6 \%$ \\
$Q_{t+6}$ & & 0.216 & 0.191 & $88.3 \%$ \\
$Q_{t+12}$ & & 0.244 & 0.219 & $89.7 \%$ \\
$Q_{t+24}$ & 0.307 & 0.285 & $92.8 \%$ \\
$Q_{t+48}$ & & 0.445 & 0.427 & $95.9 \%$ \\
\hline
\end{tabular}

ments are conducted in a subcatchment of the Ovens River Basin in southeast Australia using the PDM. In the first group, an EnKF and an EnKS with a fixed time window are implemented to update the soil moisture storage only. In the second group, the EnKF and the EnKS are implemented to update the soil moisture and routing states simultaneously.

[48] The results show that, when only soil moisture is updated, the EnKS outperforms the EnKF. In contrast, when both soil moisture and routing storages are updated, the EnKS and EnKF give very similar results. This implies that the EnKS outperforms the EnKF when the assimilation is structured in a way that bypasses the processes (routing), leading to the lag but that when the time delaying processes (routing) are included in the assimilation setup, the timelagged errors can be effectively corrected by the EnKF. This means that there is no significant difference in performance between the EnKF and the EnKS when they are applied to update soil moisture and routing stores.

[49] These two approaches are then examined for GR4H which uses a combined unit-hydrograph and storage-based routing scheme. In this case, even though the soil moisture and the routing stores are updated simultaneously, the results show that the EnkS performed better than the EnKF.

[50] Based on the results, the following conclusions are drawn. Ignoring the time lag in discharge assimilation causes overcorrection of soil moisture unless the routing process is updated directly. The implementation of the EnKS, which accounts for the time lag, improves the accuracy of both the soil moisture states and the forecast discharge, compared with the EnKF. The EnKS and EnKF become equally effective in terms of stream discharge prediction and forecasting when the routing states are updated along with the soil moisture state. However, the EnKS still results in an improved reanalysis of the antecedent soil moisture states, even when both the routing and soil moisture states are updated. In other words, although there is no added value in updating past states for improving forecast discharge when the routing states are updated, updating the past states does improve reanalysis.

[51] It has been previously noted that the routing time lag can be an issue when routing does not employ dynamic states as in the unit-hydrograph-based models [Pauwels and De Lannoy, 2009; Weerts and El Serafy, 2006] or when routing states could not be easily included in the data assimilation system [Clark et al., 2008]. To our knowledge, this is the first time the EnKS has been implemented and proven to be effective in addressing the time-lag issue, although its potential has been mentioned a few times [Lee et al., 2012; Pauwels and De Lannoy, 2006; Rakovec et al., 2012]. Further, where EnKF-based approaches have updated both the routing and soil moisture stores, it was found that the EnKF-based streamflow assimilation mainly changed the routing stores [Rakovec et al., 2012], and it remained unclear whether the EnKF-based approach effectively addressed the time-lag issue. We show in this work that the EnKF-based assimilation can effectively correct the soil moisture error accumulated in the routing states, suggesting that the time lag is effectively accounted for.

[52] The improvement achieved by using the EnKS against using the EnKF when routing store(s) is not updated directly can be made in a number of rainfall-runoff models commonly adopted for flood forecasting (e.g., GR4H and 
HBV). Moreover, operational real-time flood forecasting is tending to move from lumped models to distributed/semidistributed models [Rakovec et al., 2012]. This treats the larger-scale channel routing separately from the hillslope/ within-subcatchment routing, which may mean that the routing states cannot be easily updated directly [Clark et al., 2008; Lee et al., 2012]. In that case, the EnKS may provide an optimal option to address the time-lag issue effectively in state updating.

\section{Appendix A: Response Function Derivation}

\section{A1. Single Linear Storage Derivation}

[53] The basic formulation of the linear storage model is

$$
\begin{gathered}
\frac{\mathrm{d} S}{\mathrm{~d} t}=u-q, \\
q=k \cdot S,
\end{gathered}
$$

where $S$ is the storage, $u$ is the inflow rate, $q$ is the outflow rate, and $k$ is the delay parameter which is between 0 and 1 .

[54] Based on equations (A1) and (A2), the following equation can be derived:

$$
\frac{\mathrm{d} q}{\mathrm{~d} t}=k \cdot(u-q)
$$

[55] The approximate discrete form of equation (A3) is

$$
\frac{q_{t}-q_{t-1}}{\Delta t}=k \cdot\left(u_{t}-q_{t-1}\right)
$$

which can be rearranged to

$$
q_{t}-(1-k \cdot \Delta t) \cdot q_{t-1}=k \cdot u_{t} \cdot \Delta t
$$

[56] Based on equation (A5), we can theoretically derive:

$$
\begin{gathered}
q_{t-1}-(1-k \cdot \Delta t) \cdot q_{t-2}=k \cdot u_{t-1} \cdot \Delta t \\
q_{t-2}-(1-k \cdot \Delta t) \cdot q_{t-3}=k \cdot u_{t-2} \cdot \Delta t \\
\cdot \\
\cdot \\
\cdot \\
q_{t-(n-1)}-(1-k \cdot \Delta t) \cdot q_{t-n}=k \cdot u_{t-(n-1)} \cdot \Delta t
\end{gathered}
$$

[57] By elimination [i.e., $(\mathrm{A} 5 \mathrm{a})+(\mathrm{A} 5 \mathrm{~b}) \times(1-k)+$ $\left.(\mathrm{A} 5 \mathrm{c}) \times(1-k)^{2}+\ldots+(\mathrm{A} 5 \mathrm{n}) \times(1-k)^{n-1}\right], q_{t}$ can be estimated in terms of $q_{t-n}$ as

$$
\begin{aligned}
q_{t}= & k \cdot \Delta t \cdot\left[u_{t}+(1-k \cdot \Delta t) \cdot u_{t-1}+(1-k \cdot \Delta t)^{2} \cdot u_{t-2}+\ldots\right. \\
& \left.+(1-k \cdot \Delta t)^{n-1} \cdot u_{t-(n-1)}\right]+(1-k \cdot \Delta t)^{n} \cdot q_{t-n}
\end{aligned}
$$

[58] Note that as $k$ is between 0 and 1, it is easy to prove that $(1-k \cdot \Delta t)^{n} \cdot q_{t-n}$ will asymptote to 0 as the $n$ increases. Thus, we can infer that $q_{0}$ is a combination of $u_{t}$, $u_{t-1}, u_{t-2}, \ldots$, and $u_{t-(n-1)}$ with decreasing weights $k \cdot \Delta t$, $k \cdot \Delta t \cdot(1-k \cdot \Delta t), \quad k \cdot \Delta t \cdot(1-k \cdot \Delta t)^{2}, \quad \ldots, \quad$ and $k \cdot \Delta t \cdot(1-k \cdot \Delta t)^{n-1}$.

[59] These weights can be written as a function of steps back in time $(m)$ :

$$
f(m)=k \cdot \Delta t \cdot(1-k \cdot \Delta t)^{m-1} \quad m=1,2 \ldots n .
$$

\section{A2. Two Linear Storages Derivation}

[60] For a model with two linear storages, there are two delay parameters $k_{1}$ and $k_{2}$. Based on equation (A6), the outflow of the first and second storages, respectively, can be represented as

$$
\begin{aligned}
q_{t}= & k_{1} \cdot \Delta t \cdot\left[u_{t}+\left(1-k_{1} \cdot \Delta t\right) \cdot u_{t-1}+\left(1-k_{1} \cdot \Delta t\right)^{2} \cdot u_{t-2}+\ldots\right. \\
& \left.+\left(1-k_{1} \cdot \Delta t\right)^{n-1} \cdot u_{t-(n-1)}\right]+\left(1-k_{1} \cdot \Delta t\right)^{n} \cdot q_{t-n}
\end{aligned}
$$

$$
\begin{aligned}
q_{t}^{\prime}= & k_{2} \cdot \Delta t \cdot\left[q_{t}+\left(1-k_{2} \cdot \Delta t\right) \cdot q_{t-1}+\left(1-k_{2} \cdot \Delta t\right)^{2} \cdot q_{t-2}+\ldots\right. \\
& \left.+\left(1-k_{2} \cdot \Delta t\right)^{n-1} \cdot q_{t-(n-1)}\right]+\left(1-k_{2} \cdot \Delta t\right)^{n} \cdot q_{t}^{\prime},
\end{aligned}
$$

[61] Then $q_{t}, q_{t-1}, \ldots, q_{t-n}$ in equation (A9) can be substituted by equation (A8):

$$
\begin{aligned}
q_{t}^{\prime}= & f(1) \cdot u_{t}+f(2) \cdot u_{t-1}+f(3) \cdot u_{t-2}+\ldots+f(n) \cdot u_{t-(n-1)} \\
& +n k_{2} \cdot \Delta t \cdot\left(1-k_{1} \cdot \Delta t\right) q_{t-n}+\left(1-k_{1} \cdot \Delta t\right)^{n} \cdot q_{t-n} .
\end{aligned}
$$

[62] It is also easy to prove that $n k_{2} \cdot \Delta t$. $\left(1-k_{1} \cdot \Delta t\right) q_{t-n}$ and $\left(1-k_{1} \cdot \Delta t\right)^{n} \cdot q_{t-n}$ will asymptote to 0 as the $n$ increases. Thus, $q_{t}^{\prime}$ can be approximated by a weighted average of past inflow $u$ :

$$
q_{t}^{\prime} \approx \sum_{m=1}^{n} f(m) \cdot u_{t-(m-1)}
$$

where the weighting coefficients can be expressed as a function of steps back in time $(m)$ :

$f(m)=$
$\begin{cases}k_{1} \cdot k_{2} \cdot\left[\left(1-k_{1} \cdot \Delta t\right)^{m}-\left(1-k_{2} \cdot \Delta t\right)^{m}\right] \cdot \Delta t /\left(k_{2}-k_{1}\right) & k_{1} \neq k_{2}, \\ k^{2} \cdot m \cdot(1-k \cdot \Delta t)^{m-1} \cdot(\Delta t)^{2} & k_{1}=k_{2},\end{cases}$

where $m=1,2,3, \ldots n ; \Delta t$ is the model time step, which is $1 \mathrm{~h}$ in our study.

[63] Acknowledgments. This work was financially supported by a research contract with CSIRO. The authors would like to thank two anonymous reviewers and the Associate Editor for their constructive comments that significantly improved this paper.

\section{References}

Anctil, F., C. Perrin, and V. Andreassian (2003), Ann output updating of lumped conceptual rainfall/runoff forecasting models, J. Am. Water 
Resour. Assoc., 39(5), 1269-1279, doi:10.1111/j.1752-1688.2003. tb03708.x.

Andreadis, K. M., E. A. Clark, D. P. Lettenmaier, and D. E. Alsdorf (2007), Prospects for river discharge and depth estimation through assimilation of swath-altimetry into a raster-based hydrodynamics model, Geophys. Res. Lett., 34, L10403, doi:10.1029/2007GL029721.

Andrieu, C., A. Doucet, and R. Holenstein (2010), Particle Markov chain Monte Carlo methods, J.R. Stat. Soc. Ser. B, 72(73), 269-342.

Bogner, K., and M. Kalas (2008), Error-correction methods and evaluation of an ensemble based hydrological forecasting system for the Upper Danube catchment, Atmos. Sci. Lett., 9(2), 95-102, doi:10.1002/asl.180.

Broersen, P. M. T. (2007), Error correction of rainfall-runoff models with the ARMAsel program, IEEE Trans. Instrum. Meas., 56(6), 2212-2219, doi:10.1109/tim.2007.908252.

Burnash, R. J. C., R. L. Ferral, and R. A. McGuire (1973), A generalized streamflow simulation system: Conceptual models for digital computers, Report, 204 pp., Jt. Fed.-State River Forecast Center, Natl. Weather Serv. and State of Calif. Dep. of Water Resour., Sacramento, Calif.

Clark, M. P., A. G. Slater, A. P. Barrett, L. E. Hay, G. J. McCabe, B. Rajagopalan, and G.H. Leavesley (2006), Assimilation of snow covered area information into hydrologic and land-surface models, Adv. Water. Resour., 29(8), 1209-1221, doi:10.1016/j.advwatres.2005.10.001.

Clark, M. P., D. E. Rupp, R. A. Woods, X. Zheng, R. P. Ibbitt, A. G. Slater, J. Schmidt, and M. J. Uddstrom (2008), Hydrological data assimilation with the ensemble Kalman filter: Use of streamflow observations to update states in a distributed hydrological model, Adv. Water Resour., 31(10), 1309-1324, doi:10.1016/j.advwatres.2008.06.005.

Crow, W. T., and D. Ryu (2009), A new data assimilation approach for improving runoff prediction using remotely-sensed soil moisture retrievals, Hydrol. Earth Syst. Sci., 13(1), 1-16, doi:10.5194/hess-13-1-2009.

DeChant, C. M., and H. Moradkhani (2011), Radiance data assimilation for operational snow and streamflow forecasting, Adv. Water Resour., 34(3), 351-364, doi:10.1016/j.advwatres.2010.12.009.

DeChant, C. M., and H. Moradkhani (2012), Examining the effectiveness and robustness of sequential data assimilation methods for quantification of uncertainty in hydrologic forecasting, Water Resour. Res., 48, W04518, doi:10.1029/2011WR011011.

Duan, Q., S. Sorooshian, and V. Gupta (1992), Effective and efficient global optimization for conceptual rainfall-runoff models, Water Resour. Res., 28(4), 1015-1031, doi:10.1029/91WR02985.

Dunne, S., and D. Entekhabi (2006), Land surface state and flux estimation using the ensemble Kalman smoother during the Southern Great Plains 1997 field experiment, Water Resour. Res., 42, W01407, doi:10.1029 $2005 \mathrm{wr} 004334$

Evensen, G. (1994), Sequential data assimilation with a nonlinear quasigeostrophic model using Monte Carlo methods to forecast error statistics, J. Geophys. Res., 99(C5), 10,143-10,162, doi:10.1029/94JC00572.

Evensen, G., and P. J. van Leeuwen (2000), An ensemble Kalman smoother for nonlinear dynamics, Mon. Weather Rev., 128(6), 1852-1867, doi: 10.1175/1520-0493(2000)128<1852:AEKSFN >2.0.CO;2.

Goswami, M., K. M. O'Connor, K. P. Bhattarai, and A. Y. Shamseldin (2005), Assessing the performance of eight real-time updating models and procedures for the Brosna River, Hydrol. Earth Syst. Sci., 9(4), 394411, doi: 10.5194/hess-9-394-2005.

He, M., T. S. Hogue, S. A. Margulis, and K. J. Franz (2012), An integrated uncertainty and ensemble-based data assimilation approach for improved operational streamflow predictions, Hydrol. Earth Syst. Sci., 16(3), 815831, doi: 10.5194/hess-16-815-2012.

Komma, J., G. Bloschl, and C. Reszler (2008), Soil moisture updating by ensemble Kalman filtering in real-time flood forecasting, J. Hydrol., 357(3-4), 228-242, doi:10.1016/j.jhydrol.2008.05.020.

Kostov, K. G., and T. J. Jackson (1993), Estimating profile soil moisture from surface-layer measurements: A review, in Proceedings of the International Society for Optical Engineering, edited by H.N. Nasr, pp. 125136, Orlando, Fla

Lee, H., D.-J. Seo, and V. Koren (2011), Assimilation of streamflow and in situ soil moisture data into operational distributed hydrologic models: Effects of uncertainties in the data and initial model soil moisture states, $A d v$ Water Resour, 34(12), 1597-1615, doi:10.1016/j.advwatres.2011.08.012.

Lee, H., D. J. Seo, Y. Liu, V. Koren, P. McKee, and R. Corby (2012), Variational assimilation of streamflow into operational distributed hydrologic models: Effect of spatiotemporal scale of adjustment, Hydrol. Earth Syst. Sci., 16(7), 2233-2251, doi:10.5194/hess-16-2233-2012.

Li, Y., D. Ryu, Q.J. Wang, P. Thomas, W.A. Western, P. Hapuarachchi, and P. Toscas (2011), Assimilation of streamflow discharge into a contin- uous flood forecasting model, in Proceedings of Symposium H03 of IUGG GA 2011 in Melbourne, edited by G. Blöschl et al., pp. VI-276 p., IAHS Publ., Melbourne, Australia.

Lindström, G., B. Johansson, M. Persson, M. Gardelin, and S. Bergström (1997), Development and test of the distributed HBV-96 hydrological model, J. Hydrol., 201(1-4), 272-288, doi:10.1016/s0022-1694(97) 00041-3.

Moore, R. J. (2007), The PDM rainfall-runoff model, Hydrol. Earth Syst. Sci., 11(1), 483-499, doi: 10.5194/hess-11-483-2007.

Moradkhani, H., K. L. Hsu, H. Gupta, and S. Sorooshian (2005a), Uncertainty assessment of hydrologic model states and parameters: Sequential data assimilation using the particle filter, Water Resour. Res., 41, W05012, doi:10.1029/2004WR003604.

Moradkhani, H., S. Sorooshian, H. V. Gupta, and P. R. Houser (2005b), Dual state-parameter estimation of hydrological models using ensemble Kalman filter, Adv. Water Resour., 28(2), 135-147, doi:10.1016/j.advwatres. 2004.09.002.

Moradkhani, H., C. M. DeChant, and S. Sorooshian (2012), Evolution of ensemble data assimilation for uncertainty quantification using the particle filter-Markov chain Monte Carlo method, Water Resour. Res., 48, W12520, doi:10.1029/2012WR012144.

Nagler, T., H. Rott, P. Malcher, and F. Muller (2008), Assimilation of meteorological and remote sensing data for snowmelt runoff forecasting, Remote Sens. Environ., 112(4), 1408-1420, doi:10.1016/j.rse.2007. 07.006 .

Pagano, T., P. Hapuarachchi, and Q. Wang (2010), Continuous rainfall-runoff model comparison and short-term daily streamflow forecast skill evaluation, CSIRO Tech. Rep. EP103545, 70 pp., CSIRO, Australia.

Parajka, J., V. Naeimi, G. Bloschl, W. Wagner, R. Merz, and K. Scipal (2006), Assimilating scatterometer soil moisture data into conceptual hydrologic models at the regional scale, Hydrol. Earth Syst. Sci., 10(3), 353-368, doi:10.5194/hess-10-353-2006.

Pauwels, V. R. N., and G. J. M. De Lannoy (2006), Improvement of modeled soil wetness conditions and turbulent fluxes through the assimilation of observed discharge, J. Hydrometeorol., 7(3), 458-477, doi:10.1175/JHM490.1.

Pauwels, V. R. N., and G. J. M. De Lannoy (2009), Ensemble-based assimilation of discharge into rainfall-runoff models: A comparison of approaches to mapping observational information to state space, Water Resour. Res., 45, W08428, doi:10.1029/2008WR007590.

Pauwels, V. R. N., R. Hoeben, N. E. C. Verhoest, and F.P. De Troch (2001), The importance of the spatial patterns of remotely sensed soil moisture in the improvement of discharge predictions for small-scale basins through data assimilation, J. Hydrol., 251(1-2), 88-102, doi:10.1016/s00221694(01)00440-1.

Perrin, C., C. Michel, and V. Andréassian (2003), Improvement of a parsimonious model for streamflow simulation, J. Hydrol., 279(1-4), 275289, doi:10.1016/s0022-1694(03)00225-7.

Pilgrim, D. H. (1998), Australian Rainfall and Runoff : A Guide to Flood Estimation, Inst. of Engineers, Barton, ACT, Australia.

Rakovec, O., A. H. Weerts, P. Hazenberg, P. J. J. F. Torfs, and R. Uijlenhoet (2012), State updating of a distributed hydrological model with ensemble Kalman filtering: Effects of updating frequency and observation network density on forecast accuracy, Hydrol. Earth Syst. Sci., 16(9), 3435-3449, doi:10.5194/hess-16-3435-2012.

Reichle, R. H. (2008), Data assimilation methods in the Earth sciences, Adv. Water. Resour., 31(11), 1411-1418, doi:10.1016/j.advwatres.2008. 01.001 .

Salamon, P., and L. Feyen (2009), Assessing parameter, precipitation, and predictive uncertainty in a distributed hydrological model using sequential data assimilation with the particle filter, J. Hydrol., 376(3-4), 428442, doi:10.1016/j.jhydrol.2009.07.051.

Schoups, G., and J. A. Vrugt (2010), A formal likelihood function for parameter and predictive inference of hydrologic models with correlated, heteroscedastic, and non-Gaussian errors, Water Resour. Res., 46(10), doi: $10.1029 / 2009$ WR008933.

Schuurmans, J. M., P. A. Troch, A. A. Veldhuizen, W. G. M. Bastiaanssen, and M.F. P. Bierkens (2003), Assimilation of remotely sensed latent heat flux in a distributed hydrological model, Adv. Water. Resour., 26(2), 151-159, doi:10.1016/S0309-1708(02)00089-1.

Sene, K. (2008), Flood Warning, Forecasting and Emergency Response, Springer, Berlin

Seo, D.-J., V. Koren, and N. Cajina (2003), Real-time variational assimilation of hydrologic and hydrometeorological data into operational hydrologic forecasting, J. Hydrometeorol., 4(3), 627-641, doi:10.1175/15257541(2003)004<0627:RVAOHA $>2.0 . \mathrm{CO} ; 2$. 
Seo, D.-J., L. Cajina, R. Corby, and T. Howieson (2009), Automatic state updating for operational streamflow forecasting via variational data assimilation, J. Hydrol., 367(3-4), 255-275, doi:10.1016/j.jhydrol.2009.01.019.

Shamseldin, A. Y., and K. M. O'Connor (2001), A non-linear neural network technique for updating of river flow forecasts, Hydrol. Earth Syst. Sci., 5(4), 577-597, doi:10.5194/hess-5-577-2001.

Slater, A. G., and M. P. Clark (2006), Snow data assimilation via an ensemble Kalman filter, J. Hydrometeorol., 7(3), 478-493, doi:10.1175/JHM505.1.

Thirel, G., E. Martin, J. F. Mahfouf, S. Massart, S. Ricci, and F. Habets (2010), A past discharges assimilation system for ensemble streamflow forecasts over France. Part 1: Description and validation of the assimilation system, Hydrol. Earth Syst. Sci., 14(8), 1623-1637, doi:10.5194/ hess-14-1623-2010.

Vrugt, J. A., C. G. H. Diks, H. V. Gupta, W. Bouten, and J. M. Verstraten (2005), Improved treatment of uncertainty in hydrologic modeling: Combining the strengths of global optimization and data assimilation, Water Resour. Res., 41, W01017, doi:10.1029/2004WR003059.

Vrugt, J. A., H. V. Gupta, and B. O. Nuallain (2006), Real-time data assimilation for operational ensemble streamflow forecasting, J. Hydrometeorol., 7(3), 548-565, doi:10.1175/JHM504.1.
Vrugt, J. A., C. J. F. ter Braak, C. G. H. Diks, and G. Schoups (2013), Hydrologic data assimilation using particle Markov chain Monte Carlo simulation: Theory, concepts and applications, $A d v$. Water Resour., 51(0), 457-478, doi:http://dx.doi.org/10.1016/ j.advwatres.2012.04.002.

Wagener, T., D. P. Boyle, M. J. Lees, H. S. Wheater, H. V. Gupta, and S. Sorooshian (2001), A framework for development and application of hydrological models, Hydrol. Earth Syst. Sci., 5(1), 13-26, doi:10.5194/ hess-5-13-2001.

Weerts, A. H., and G. Y. H. El Serafy (2006), Particle filtering and ensemble Kalman filtering for state updating with hydrological conceptual rainfall-runoff models, Water Resour. Res., 42, W09403, doi:10.1029/ 2005WR004093.

Xie, X. H., and D. X. Zhang (2010), Data assimilation for distributed hydrological catchment modeling via ensemble Kalman filter, Adv. Water. Resour., 33(6), 678-690, doi:10.1016/j.advwatres.2010.03.012.

Zhang, Y., F. H. S. Chiew, L. Zhang, and H. Li (2009), Use of remotely sensed actual evapotranspiration to improve rainfall-runoff modeling in Southeast Australia, J. Hydrometeorol., 10(4), 969-980, doi:10.1175/ 2009JHM1061.1. 


\section{University Library}

\section{- M M I N E R VA A gateway to Melbourne's research publications}

Minerva Access is the Institutional Repository of The University of Melbourne

\section{Author/s:}

Li, Y;Ryu, D;Western, AW;Wang, QJ

Title:

Assimilation of stream discharge for flood forecasting: The benefits of accounting for routing time lags

Date:

2013-04-01

\section{Citation:}

Li, Y., Ryu, D., Western, A. W. \& Wang, Q. J. (2013). Assimilation of stream discharge for flood forecasting: The benefits of accounting for routing time lags. WATER RESOURCES RESEARCH, 49 (4), pp.1887-1900. https://doi.org/10.1002/wrcr.20169.

Persistent Link:

http://hdl.handle.net/11343/297405 